\title{
Comparison of Three Dynamic Models of Political Development
}

\author{
Jiancheng Liu \\ Dongfang Boiler Co., Ltd., Zigong, China \\ Email:decljc@163.com
}

How to cite this paper: Liu, J.C. (2022) Comparison of Three Dynamic Models of Political Development. Open Access Library Journal, 9: e8276.

https://doi.org/10.4236/oalib.1108276

Received: December 6, 2021

Accepted: January 1, 2022

Published: January 4, 2022

Copyright (C 2022 by author(s) and Open Access Library Inc.

This work is licensed under the Creative Commons Attribution International License (CC BY 4.0).

http://creativecommons.org/licenses/by/4.0/

\section{(c) (i) Open Access}

\begin{abstract}
This is a paper relative to political development dynamics, introduces the political development dynamics from two aspects of capitalism and socialism, and briefly introduces the political development of China. Put forward three Dynamic Models of Political Development, respectively analyze the motive powers of developing capitalist countries, developed capitalist countries and socialist countries, and induce and summarize the Socialist Core Thought.
\end{abstract}

\section{Subject Areas}

Development Economics, Economics, Political Economy

\section{Keywords}

Dynamic Models of Political Development, Developing Capitalist Countries, Developed Capitalist Countries, Socialist Countries and Socialist Core Thought

\section{1. 政治发展动力学模型}

在中国知网(https://www.cnki.net/)输入关键词 “政治发展动力学模型” 进 行检索, 没有查到任何相关的内容(截图 1); 而输入关键词 “政治发展动力” + “模型” 进行检索, 只查到 2 篇相关文献(高申茂, 2019 [1]和罗大蒙、张芸, 2016 [2], 截图 2)。所以, 本文的分析是完全原创性的研究。

就社会制度而言, 全世界存在两种制度一一资本主义制度和社会主义制 度。资本主义国家又分为发展中国家和发达国家。对发展中资本主义国家来 说, 上层统治阶级占少数, 中产阶级占一定比例, 而下层民众占多数, 故其 政治发展动力学模型为金字塔形(图 1(a)); 对发达资本主义国家来说, 上层统 治阶级占少数, 中产阶级占多数, 下层民众占一定比例, 其政治发展动力学 模型为橄榄形(图 1(b))。社会主义国家人人平等, 以国家最高领导人为核心, 
在共产党领导下，全国人民紧密团结在其周围，其政治发展动力学模型为同 心圆(图 2)。

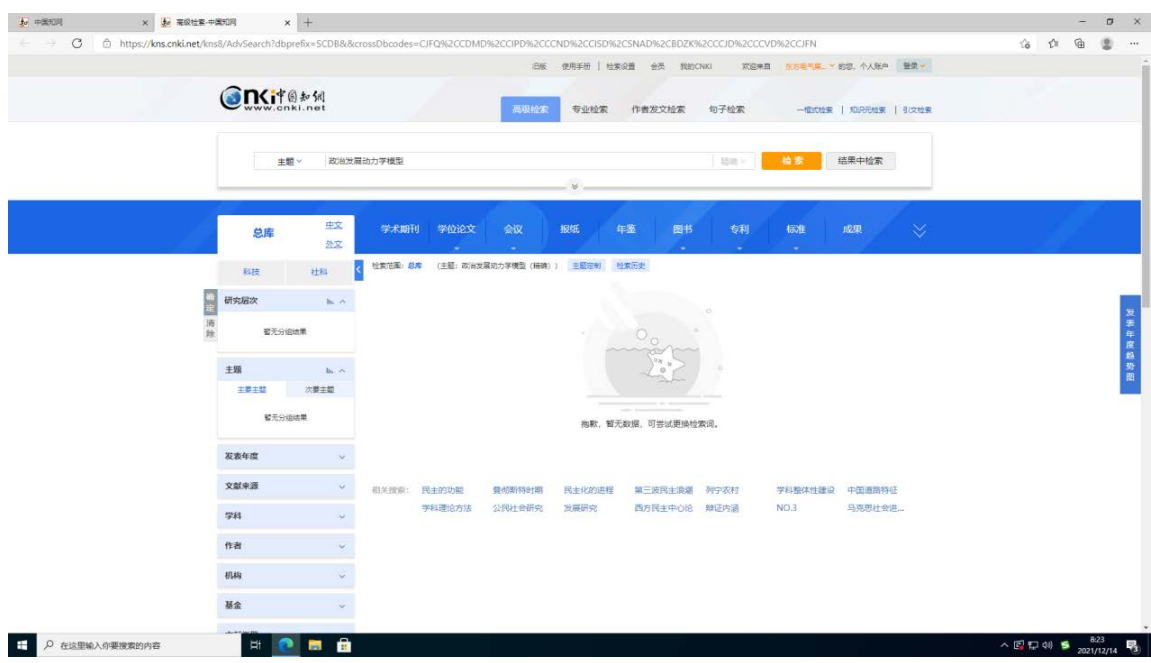

截图 1.

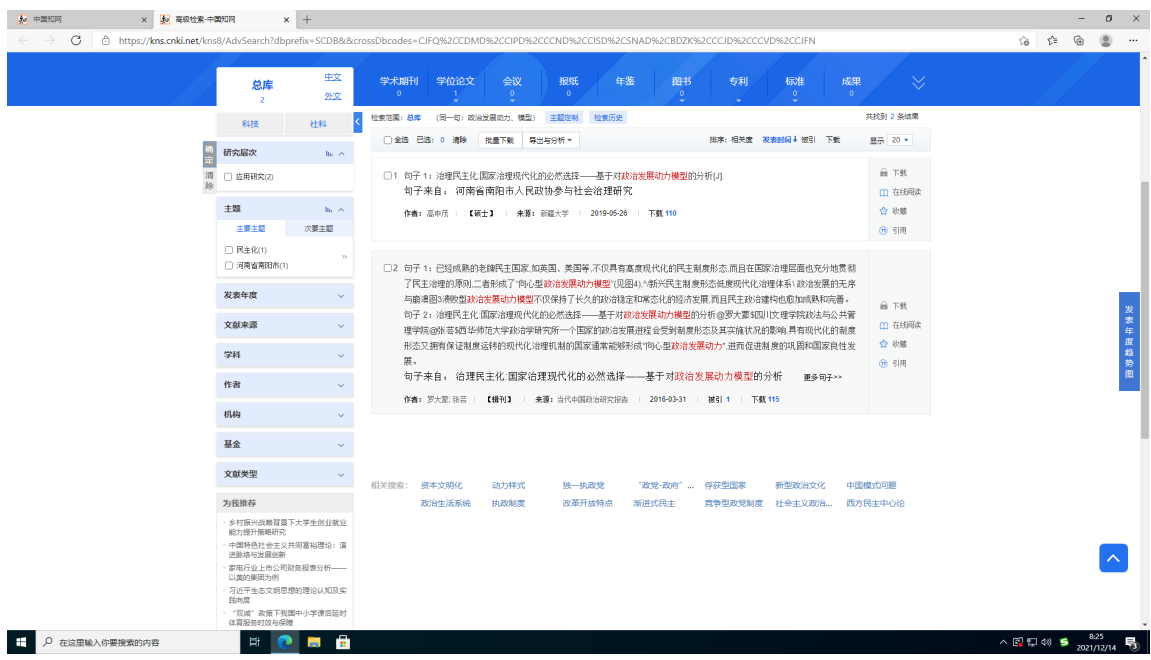

截图 2.

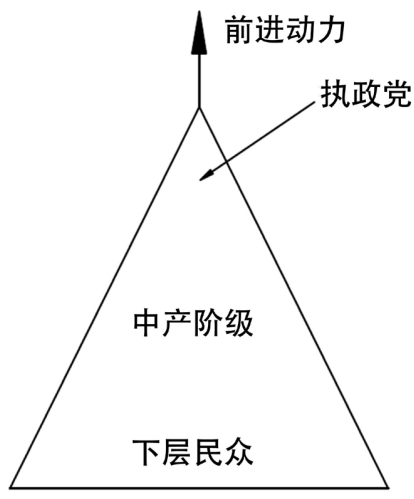

(a)

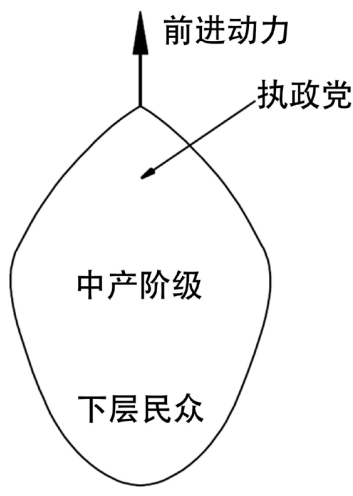

(b)

图 1. (a) 发展中国家(图片为作者首创)；(b) 发达国家(图片为作者首创) 


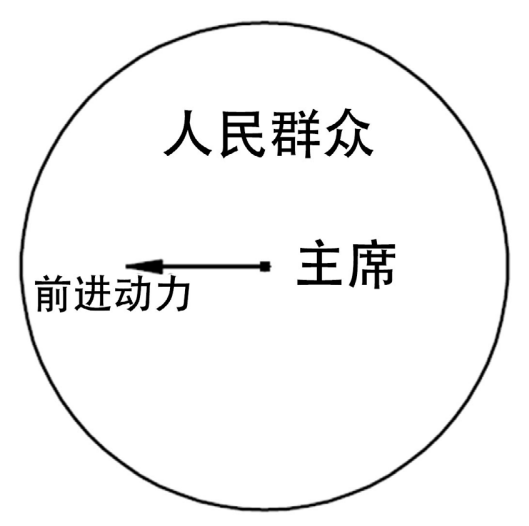

图 2. 社会主义国家(图片为作者首创)

\section{2. 政治发展动力分析}

\section{1. 发展中资本主义国家}

在发展中的资本主义国家, 政治发展的前进动力主要来自执政党的意志, 而其它政党通常成为阻力, 多数情况下, 广大民众的意志并不统一。同时, 由于多党轮流执政, 国家政治发展的方向并不明确。所以, 发展中资本主义 国家只能在执政党的意志拖动下断续前进, 经济社会发展速度不稳定、发展 质量不高。

\section{2. 发达资本主义国家}

在发达资本主义国家, 政治发展的前进动力主要来自执政党及社会精英 阶层的意志, 而其它政党通常也成为阻力, 广大民众(中产阶级和社会底层) 的意志也不统一。由于多党(两党)轮流执政, 国家政治发展方向并不确定。 所以, 发达资本主义国家只能在执政党及社会精英阶层的意志拉动下断续前 进, 经济社会发展速度不稳定、发展方向不明确。

\section{3. 社会主义国家}

在社会主义国家, 特别是在中国, 政治发展的前进动力来自党和国家最 高领导人及全国人民的意志, 而参政党通常成为肋力, 在共产党领导下, 广 大人民群众意志统一。由于为一党执政, 国家政治发展方向明确。所以, 社 会主义国家在党和国家最高领导人及全国人民的意志驱动下持续滚动前进, 经济社会发展速度快、发展质量高、发展方向明确。

\section{3. 中国的政治发展}

马克思列宁主义是信仰, 毛泽东思想是武器, 邓小平理论是方向, 三个 代表思想是要求, 科学发展观是方法, 习近平新时代中国特色社会主义思想 是目标, 统一于社会主义核心思想, 是中国共产党的行动方针和指导思想。

一种信仰: 共产主义

两把武器: 矛盾论、实践论

一个方向：建设中国特色社会主义 
三项要求：始终代表中国先进生产力的发展要求;

始终代表中国先进文化的前进方向;

始终代表中华民族的根本利益。

两套方法: 科学发展, 全面管理

两个百年目标：实现中华民族伟大复兴是中华民族近代以来最伟大的梦 想。在中国共产党成立一百年时全面建成小康社会，这是中国梦的第一个宏 伟目标; 在中华人民共和国成立一百年时建成富强民主文明美丽的社会主义 现代化强国, 这是中国梦的第二个宏伟目标。

人与自然和谐发展, 是统治人类和自然的最高规律。坚持五大发展理念: 崇尚创新、注重协调、倡导绿色、厚植开放、推进共享。人们日益增长的物 质文化需要同相对落后的社会生产之间的矛盾, 始终是任何社会的主要矛盾, 是经济社会发展的根本动力。

现阶段中国社会的主要矛盾集中体现在生产关系方面, 即收入分配不公 严重伤害了广大劳动者的生产积极性并制约了经济社会的良性发展。不平衡 不充分发展的根本原因, 也在于差距过大不公平的收入分配体系。各尽所能, 按劳分配, 才是中国特色社会主义根本区别于西方资本主义的基本分配原则。

一个中心, 四个基本点, 即以经济建设为中心, 坚持社会主义道路, 坚 持人民民主专政，坚持中国共产党的领导，坚持社会主义核心思想，是立国 之本; 坚持改革开放, 是强国之路。

社会主义经济建设、政治建设、文化建设、社会建设、生态建设、党的 建设、人民军队建设和质量工程建设八位一体, 缺一不可。质量工程建设贯 穿于经济建设、政治建设、文化建设、社会建设、生态建设、党的建设和人 民军队建设的始终, 是经济建设、政治建设、文化建设、社会建设、生态建 设、党的建设和人民军队建设的灵魂。

以人的品质保工作质量, 以工作质量保产品质量, 以产品质量保生活质 量, 以生活质量促人的品质提高, 循环往复, 周而复始, 最终实现从必然王 国向自由王国的飞跃！

\section{4. 分析结论}

发展中资本主义国家只能在执政党的意志拖动下断续前进, 需克服较大 的滑动摩擦阻力, 经济社会发展速度不稳定、发展质量不高。发达资本主义 国家只能在执政党及社会精英阶层的意志拉动下断续前进，同样需克服较大 的滑动摩擦阻力, 经济社会发展速度不稳定、发展方向不明确。而社会主义 国家在党和国家最高领导人及全国人民的意志驱动下持续滚动前进，只需克 服较小的滚动摩擦阻力, 经济社会发展速度快、发展质量高、发展方向明确。

\section{Conflicts of Interest}

The author declares no conflicts of interest.

\section{References}

[1] 高申茂. 河南省南阳市人民政协参与社会治理研究[D]: [硕士学位论文]. 乌鲁木 
齐: 新疆大学, 2019.

[2] 罗大蒙, 张芸. 治理民主化: 国家治理现代化的必然选择一一基于政治发展动力 模型的分析[R]. 当代中国政治研究报告, 2016 .

\section{Appendix}

\section{三种政治发展动力学模型比较}

摘要: 这是一篇与政治发展动力学相关的文章, 从资本主义和社会主义两个 方面介绍了政治发展动力学，并简要介绍了中国的政治发展。提出三种政治 发展动力学模型, 分别对发展中资本主义国家、发达资本主义国家和社会主 义国家的政治发展动力进行了分析，并对社会主义核心思想进行了归纳和总 结。

关键词: 政治发展动力学模型, 发展中资本主义国家, 发达资本主义国家, 社会主义国家, 社会主义核心思想 